\title{
Congenital heart disease: an ageing problem
}

\author{
Gabrielle Norrish, Juan Pablo Kaski
}

\begin{abstract}
Author
Gabrielle Norrish

Research Fellow in Inherited

Cardiovascular Disease

Juan Pablo Kaski

Consultant Paediatric Cardiologist and Honorary Senior Lecturer

Centre for Inherited

Cardiovascular Diseases, Great

Ormond Street Hospital, London,

WC1N 3JH
\end{abstract}

Correspondence to:

Dr J P Kaski

(j.kaski@ucl.ac.uk)

\section{Key words}

ageing, congenital heart disease, survival

doi: 10.5837/bjc.2018.015

Br J Cardiol 2018;25:(2)
C ongenital heart disease (CHD) is the most common congenital anomaly, with an estimated prevalence of eight per 1,000 births. ${ }^{1}$ However, reliable data on long-term survival for this heterogeneous group of patients are still lacking. Previous population-based studies from the US reported age-standardised mortality rates secondary to CHD of 1.2 per $100,000 .^{2}$ Mortality was highest during infancy $(48.1 \%$ of all deaths occurred under the age of one year), however, the majority of the remaining deaths occurred outside of childhood, following transition to adult care. Yet, while it is accepted that individuals with CHD may have a higher mortality compared with the general population, the wide spectrum of disease means interpretation of population-based mortality rates for individual lesions is difficult. Additionally, a significant number of studies report only on shortterm follow-up, meaning that long-term outcomes are unknown. A previous systematic review reported pooled survival estimates for common CHD lesions, however, it only included studies from hospital-based cohorts with survival estimates calculated from the time of surgical repair. ${ }^{3}$ It, therefore, does not account for those patients who do not need surgical intervention and may not be representative of all patients with $\mathrm{CHD}$. Knowing the expected mortality rates for $\mathrm{CHD}$ is not only important for family counselling, but also in service planning.

It is, therefore, with interest that we read the meta-analysis of long-term survival of individuals born with CHD by Best and Rankin. ${ }^{4}$ Utilising population-based studies, they report a pooled oneyear, five-year and 10-year survival for all CHD of $87 \%, 85.4 \%$ and $81.4 \%$, respectively. The survival estimates for individual CHD lesions differed, with 'high-risk lesions', such as tricuspid atresia or common arterial trunk, having a poorer survival than 'simple lesions', such as atrial septal defect (ASD) or ventricular septal defect (VSD), confirming what is seen in clinical practice. There were some surprising findings, including a worse than expected outcome for patients with transposition of the great arteries (TGA) (one-year survival 76\%) and

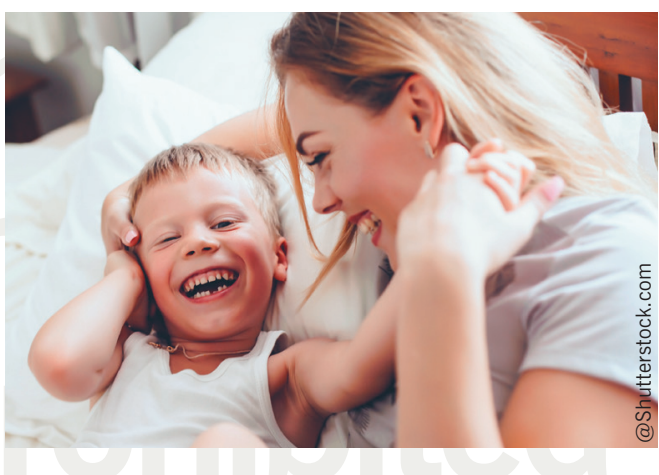

hypoplastic left heart syndrome (HLHS) (one-year survival $17.4 \%$ ). However, as this meta-analysis includes patients born from 1977 to 2007, this likely reflects a historical cohort that is not comparable with contemporary cohorts.

\section{Advances}

Meta-regression analysis showed that there was a positive association between study year and higher survival, with improved survival for all lesions over time. The improved outcomes of CHD in childhood over time are well described. Indeed, since the first ligation of a patent ductus arteriosus in 1938 by Dr Gross, the surgical management of patients with $\mathrm{CHD}$ has evolved remarkably. This is particularly true for complex lesions such as TGA, which prior to the first definitive atrial baffle repairs by Senning $(1959)^{5}$ and Mustard $(1964)^{6}$ had a poor outlook. Subsequently, in 1975, Jatene et al. ${ }^{7}$ described the first successful anatomic repair using microvascular techniques to transfer the coronary buttons to the neoaorta. Today, the arterial switch operation is performed early, usually in the first two weeks of life, and has transformed the care and outlook of these infants. A similar story of surgical development leading to improved survival can be told for almost all CHD lesions.

Of course, surgical developments have not occurred in isolation. Similar advances have been made in interventional techniques for $\mathrm{CHD}$ from the first balloon atrial septostomy by Rashkind in 1966,8 which palliated patients for long enough to wait for surgical repair, to techniques that avoid the need 
EDITORIAL BJC ONLINE

for repeat operations, such as percutaneous pulmonary valve implantation pioneered by Bonhoeffer in 2000. ${ }^{9}$

Additionally, over this same time period antenatal detection of $\mathrm{CHD}$ lesions has also improved. The latest NICOR (National Institute for Cardiovascular Outcomes Research) data from 2014 reported that $47 \%$ of children in the UK requiring surgery or intervention within the first year of life for CHD were diagnosed antenatally. ${ }^{10}$ However, these figures do not account for those that die without, or those that do not require, intervention. There is conflicting evidence about the effect of improved antenatal detection on mortality rates for $\mathrm{CHD}$. In certain lesions, such as TGA, a significant reduction in both preoperative and postoperative mortality is associated with an antenatal diagnosis. ${ }^{11}$ However, for other lesions, such as HLHS, the evidence for improved mortality is less clear, yet an antenatal diagnosis has been shown to be associated with reduced neonatal neurological morbidity. ${ }^{12}$

Importantly, the improved survival of children with $\mathrm{CHD}$ means that the number of adults living with $\mathrm{CHD}$ is increasing. Marelli et al. reported that in a 10 -year period from 2000 to 2010 the prevalence of CHD in adults increased by $57 \%$ reaching $6.12 / 100,000 .{ }^{13}$ In fact, in 2010, there were more adults in the US with CHD than those under 18 years $(66 \%$ of entire population). Different terms are used to describe this population of patients, including grown up with congenital heart disease (GUCH) and adult congenital heart disease (ACHD). However, regardless of the label, since the 1970s it has increasingly been recognised that young people and adults with CHD need lifelong, expert medical care. This is particularly true given that many patients are not cured by their initial surgery, but instead are palliated. Indeed, Best and Rankin report that while mortality is highest in the first year of life, it continues to increase on longer follow-up. Few studies reported follow-up after five years, so estimates of longer-term mortality are lacking in this meta-analysis. However, a US population study reported that mortality secondary to CHD continued into adulthood with a mortality rate of approximately $0.55 / 100,000$ up to 65 years, at which age it increased to $1.1 / 100,000 .^{2}$ In addition to the management of their primary cardiac lesion, a significant number of these patients have additional extra-cardiac anomalies (20\% reported by Best and Rankin), which may complicate their management. There is also an increasing awareness that these children and young people are at a higher risk of neurodevelopmental disorders. ${ }^{14}$ In this setting, the development of a specialist ACHD service, which can provide expertise not only in medical and surgical management for CHD but also non-cardiac care, is a challenge. However, significant progress has been made and $\mathrm{ACHD} / \mathrm{GUCH}$ care is a rapidly increasing speciality.

\section{Transition of care}

Given the importance of lifelong care, the successful transition of patients between paediatric and adult care settings is paramount. However, multiple studies have shown that the time around transition is associated with lapses in medical care. Around the age of transition, $42 \%$ of patients with CHD self-reported a gap of more than three years in specialist cardiac care in one study. ${ }^{15}$ This is important because a period of non-attendance has been significantly associated with the diagnosis of a new haemodynamically significant lesion or need for urgent cardiac intervention. ${ }^{16}$ While there has been increased focus on transition as a comprehensive and continual process, rather than a single time point, a significant number of patients may still fail to successfully access specialist CHD care. A recent study in the UK found that one-third of adults with tetralogy of Fallot were not registered with an adult CHD clinic. ${ }^{17}$

The study by Best and Rankin has limitations; as a meta-analysis of published literature it describes survival rates for a historical cohort that may not be applicable to contemporary patient cohorts, it reports all-cause mortality and, therefore, fails to distinguish between cardiac and non-cardiac deaths, and, finally, it is not able to account for morbidity secondary to CHD. However, it provides useful trends of mortality, showing that, in agreement with other studies, the highest mortality is in infancy, but continues throughout childhood and likely into adulthood, and, second, that the prognosis for all lesions has been improving over time. While it is likely that further improvements in early childhood survival secondary to surgical or interventional developments will be seen, improvements in long-term survival for this patient group are likely to be at least partly dependent on the successful transition of them to a welldesigned ACHD service

\section{Conflict of interest}

None declared.

\section{References}

1. Dolk H, Loane M, Garne E. Congenital heart defects in Europe: prevalence and perinatal mortality, 2000 to 2005. Circulation 2011;123:841-9. https://doi.org/10.1161/ CIRCULATIONAHA.110.958405

2. Gilboa SM, Salemi JL, Nembhard WN, Fixler DE, Correa A. Mortality resulting from congenital heart disease among children and adults in the United States, 1999 to 2006. Circulation 2010;122:225463. https://doi.org/10.1161/
CIRCULATIONAHA.110.947002

3. Verheugt CL, Uiterwaal CSPM, Grobbee DE, Mulder BJM. Longterm prognosis of congenital heart defects: a systematic review. Int J Cardiol 2008;131:25-32. https://doi. org/10.1016/j.ijcard.2008.06.023

4. Best KE, Rankin J. Long-term survival of individuals born with congenital heart disease: a systematic review and meta-analysis. J Am Heart Assoc 2016;5:e002846. https://doi. org/10.1161/JAHA.115.002846

5. Senning A. Surgical correction of transposition of the great vessels.
Surgery 1959;45:966-80.

6. Mustard WT. Successful two-stage correction of transposition of the great vessels. Surgery 1964;55:469-72.

7. Jatene $A D$, Fontes VF, Paulista $\mathrm{PP}$ et al. Anatomic correction of transposition of the great vessels. J Thorac Cardiovasc Surg 1976;72:364-70.

8. Rashkind WJ, Miller WW. Creation of an atrial septal defect without thoracotomy. A palliative approach to complete transposition of the great arteries. JAMA 1966;196:991-2. https://doi.org/10.1001/ jama.1966.03100240125026

9. Bonhoeffer P, Boudjemline $Y$, Saliba $Z$ et al. Percutaneous replacement of pulmonary valve in a right-ventricle to pulmonary-artery prosthetic conduit with valve dysfunction. Lancet 2000;356:1403-05. https://doi. org/10.1016/S0140-6736(00)02844 0

10. NICOR: National Institute for Cardiovascular Outcomes Research. National congenital heart disease audit website. Antenatal diagnosis. Available at: https://nicor4.nicor.org. uk/chd/an_paeds.nsf/vwContent/ Antenatal Diagnosis?Opendocument 
11. Bonnet D, Coltri A, Butera G et al Detection of transposition of the great arteries in fetuses reduces neonatal morbidity and mortality. Circulation 1999;99:916-18. https://doi. org/10.1161/01.CIR.99.7.916

12. Mahle WT, Clancy RR, McGaurn $\mathrm{SP}$, Goin JE, Clark BJ et al. Impact of prenatal diagnosis on survival and early neurologic morbidity in neonates with the hypoplastic left heart syndrome. Pediatrics 2001;107:1277-82. https://doi. org/10.1542/peds.107.6.1277

13. Marelli AJ, lonescu-Ittu $R$, Mackie AS, Guo L, Dendukuri N, Kaouache M. Lifetime prevalence of congenital heart disease in the general population from 2000 to 2010. Circulation 2014;130:74956. https://doi.org/10.1161/ CIRCULATIONAHA.113.008396

14. Marino BS, Lipkin PH, Newburger JW et al. Neurodevelopmental outcomes in children with congenital heart disease: evaluation and management: a scientific statement from the American Heart Association. Circulation 2012;126:1143-72. https://doi.org/10.1161/ CIR.0b013e318265ee8a

15. Gurvitz M, Valente AM, Broberg $\mathrm{C}$ et al. Prevalence and predictors of gaps in care among adult congenital heart disease patients: HEARTACHD (The Health, Education, and Access Research Trial). J Am Coll Cardiol 2013;61:2180-4. https://doi. org/10.1016/j.jacc.2013.02.048

16. Yeung E, Kay J, Roosevelt GE, Brandon M, Yetman AT. Lapse of care as a predictor for morbidity in adults with congenital heart disease. Int $\mathrm{J}$ Cardiol 2008;125:62-5. https://doi. org/10.1016/j.ijcard.2007.02.023

17. Wray J, Frigiola A, Bull C. Loss to specialist follow-up in congenital heart disease; out of sight, out of mind. Heart 2013;99:485-90. https://doi. org/10.1136/heartjnl-2012-302831 